\title{
Corrigendum: The Influence of Taxonomy and Environment on Leaf Trait Variation Along Tropical Abiotic Gradients
}

\begin{abstract}
Imma Oliveras ${ }^{1 *}$, Lisa Bentley ${ }^{2}$, Nikolaos M. Fyllas ${ }^{3}$, Agne Gvozdevaite ${ }^{1}$, Alexander Frederick Shenkin ${ }^{1}$, Theresa Peprah ${ }^{4}$, Paulo Morandi ${ }^{5}$, Karine Silva Peixoto ${ }^{5}$, Mickey Boakye ${ }^{4,6}$, Stephen Adu-Bredu ${ }^{4}$, Beatriz Schwantes Marimon ${ }^{5}$, Ben Hur Marimon Junior ${ }^{5}$, Norma Salinas ${ }^{7}$, Roberta Martin ${ }^{8}$, Gregory Asner ${ }^{8}$, Sandra Díaz ${ }^{9}$, Brian J. Enquist ${ }^{10,11}$ and Yadvinder Malhi ${ }^{1}$

${ }^{1}$ Environmental Change Institute, School of Geography and the Environment, University of Oxford, Oxford, United Kingdom, ${ }^{2}$ Department of Biology, Sonoma State University, Rohnert Park, CA, United States, ${ }^{3}$ Biodiversity Conservation Laboratory, Department of Environment, University of the Aegean, Mytilene, Greece, ${ }^{4}$ Forestry Research Institute of Ghana, Council for Scientific and Industrial Research, Kumasi, Ghana, ${ }^{5}$ Laboratorio de Ecologia Vegetal (LABEV), Universidade Do Estado de Mato Grosso, Nova Xavantina, Brazil, ${ }^{6}$ Department of Environmental Science, Policy and Management, University of California, Berkeley, Berkeley, CA, United States, ${ }^{7}$ Instituto de Ciencias de la Naturaleza, Territorio y Energías Renovables, Pontificia Universidad del Perú, Lima, Perú, ${ }^{8}$ Centre for Global Discovery \& Conservation Science, Arizona State University, Tempe, AZ, United States, ${ }^{9}$ Instituto Multidisciplinario de Biologia Vegetal, Consejo Nacional de Investigaciones Científicas y Técnicas and Facultad de Ciencias Exactas, Físicas y Naturales, Universidad Nacional de Cordoba, Córdoba, Argentina, ${ }^{10}$ Department of Ecology and Evolutionary Biology, University of Arizona, Tucson, AZ, United States, ${ }^{11}$ The Santa Fe Institute, Santa Fe, NM, United States
\end{abstract}

Keywords: environmental filtering, variance partitioning, trait covariation, interspecific, intraspecific

\section{A Corrigendum on}

The Influence of Taxonomy and Environment on Leaf Trait Variation Along Tropical Abiotic Gradients

by Oliveras, I., Bentley, L., Fyllas, N. M., Gvozdevaite, A., Shenkin, A. F., Peprah, T., et al. (2020). Front. For. Glob. Change 3:18. doi: 10.3389/ffgc.2020.00018

An author's name was incorrectly spelled as "Theresa Prepah." The correct spelling is "Theresa Peprah."

In the published article, there was an error in affiliation 8. Instead of "Department of Global Ecology, Carnegie Institution for Science, Stanford, CA, United States," it should be "Centre for Global Discovery \& Conservation Science, Arizona State University, United States."

Finally, Norma Salinas was not included as an author in the published article. Their affiliation has been added as affiliation 7. The corrected Author Contributions Statement appears below.

\section{AUTHOR CONTRIBUTIONS}

IO, LB, RM, NF, BE, and YM designed the idea. IO and YM received funding to collect the data. IO performed statistical analyses. IO, LB, NS, TP, RM, and AG led field campaigns, all authors participated in field data collection. IO led the manuscript writing with significant contributions from YM, LB, and BE. All authors commented on and approved the manuscript.

The authors apologize for this error and state that this does not change the scientific conclusions of the article in any way. The original article has been updated. 
Copyright $\odot 2020$ Oliveras, Bentley, Fyllas, Gvozdevaite, Shenkin, Peprah, Morandi, Peixoto, Boakye, Adu-Bredu, Schwantes Marimon, Marimon Junior, Salinas, Martin, Asner, Díaz, Enquist and Malhi. This is an open-access article distributed under the terms of the Creative Commons Attribution License (CC BY). The use, distribution or reproduction in other forums is permitted, provided the original author(s) and the copyright owner(s) are credited and that the original publication in this journal is cited, in accordance with accepted academic practice. No use, distribution or reproduction is permitted which does not comply with these terms. 